" Whereas, according to the image in this place, the wild branches are ingrafted into the generous tree, reversing the usual process by which good branches are grafted into wild trees, we are informed by both ancient and modern writers that such a process is practicable in this very tree, the olive, and is often practised in the East. Compare Columella 'De Rebus Rusticis,' v. g." Can this be confirmed? It seems scarcely credible. The question bears on the subject of graft-hybridisation, about which many curious facts are collected in Darwin's work on "Variation under Domestication."

Old Forge, Dunmurry, Co. Antrim, June 29

\section{Wild Duck and Railways}

LAST autumn I visited Canada and made a journey to the extreme west point (then reached) of the Canada Pacific Railway, on which three or four thousand men were at the time employed laying down the rails on the prairie, at the very rapid rate of three or four miles a day, or more than twenty miles a week. There are many ponds and lakelets along the track, which abounded at that season with a variety of ducks-mallard, teal, widgeon, \&c.- - usually very shy, and not easily approached by the sportsman. Yet these ducks had in the short space of from two to five days become so accustomed to the noisy and (to most of the birds) novel engine moving along, that they remained sitting quietly in the water within easy shot when the train was passing. On my return journey I was sorry to find that this confidence on the part of the ducks was taken advantage of by the conductor and other wretched sportsmen (?) who shot at the poor birds from the platform of the cars whilst in motion, although when they did kill-I am glad to say there were more misses than hits-they could not stop to pick up the game. A sportsman, to get equally near to the ducks as they permitted the train to approach them, had to use the cover of the long grass and some artful dodging to attain his object. This quick intelligence on the part of the ducks seemed to me something remarkable, as the senses both of sight and hearing must have been, one would suppose, at first alarmingly affected by the great noisy, smoking monster rushing along their favourite and hitherto usually silent haunts.

4, Addison Gardens, June 30

\section{Large Hailstones}

A SEVERE thanderstorm passed over Woodlesford, six miles south-east of Leeds, between 3 . Io and 4 p.m. this afternoon, proceeding from south-west to north-east. Flashes of lightning during that iime were almost continuous. At 3.15 heavy rain began to fall, becoming so thick at 3.25 as to render objects a short distance away almost indistinct; at 3.30 this changed to hail, the stones during the worst period being generally irregular parallelopipeds of ice, with two edges of about one inch each, and the third of one-quarter of an inch. These blocks consisted of hard, colourless, transparent ice, surrounding a central, irregularly-shaped mass of opaque white, small air-bubbles of roughly ellipsoidal shape being ranged round this. The white nucletis was not quite so hard as the exterior transparent coating. The force of collision on the railway line was sufficient to make the masses bound to a vertical height of two or three feet. At 3.45 the hail had moderated, when a few light loose clouds were observed quickly passing from north-east to south-west, and thus directly opposite to the direction of the storm, and at a much lower level.

June 30

R. WEBв

\section{Extinction of Flatfish}

I HAVE been advised by Mr. Murray of the Challenger expedition to inquire, through your columns, whether the experience of any of your correspondents coincides with mine as to the giadual failure-in some places almost the extinetion-of flatfish where whelk-gathering is prosecuted. MALCOLM MCNEILL

The New Club, Edinburgh, June 30

\section{Garfish}

IN March last I was being pulled off from the shore to H.M.S. Himalaya in the harbour at Aden, when a fish jumped out of the water over the boat, and in doing so struck the hat of another officer and knocked it into the water. When the hat was recovered we found in the hard felt a slit about four inches in length. Unfortunately the fish escaped, but the impression of those who saw it was that it was some kind of garfish, and that the damage done was inflicted by the beak. It appeared to me to be about ten inches long. It is obvious that had the fish struck my friend in the face or neck, or even in the chest, it might have resulted in a fatal injury.

S. ARCHER

Sheerness, June 29

\section{The "Spirogyra quinina"}

CAN any of your readers inform me of any practical method of exterminating, in a lodge or reservoir, confervoid algæ, more especially the fine filamentous variety Spirogyra quinina?

Hanley, Staffordshire, June I9

FREDK. HAIGH

\section{ACTION OF LIGHT ON INDIARUBBER}

$\mathrm{IN}$ continuation of the experiments described in 1 NATURE, vol. xxvii. p. 312, two pieces of caoutchouc tube, about $48 \mathrm{~mm}$. long and $7 \mathrm{~mm}$. wide, were introduced on January 23,1883 , into test tubes containing oxygen confined over mercury. One of these tubes was surrounded by a case of black paper, and both tubes were placed side by side in a north window. On June 27 the tubes were examined : in that exposed to light about I7 cc. of oxygen (about three-quarters of the gas the test tube at first contained) had been absorbed, and the indiarubber had become altered, so that on pressing the tube between the fingers superficial cracks were produced. In the other test tube no appreciable diminution of gas had taken place, and the caoutchouc was unchanged, thus fully confirming the results of the former experiments. We may therefore conclude that caoutchouc alters under the combined influence of light and oxygen, but that neither alone produces any effect.

Cooper's Hill, June 29

\section{HERBERT MCLEOD}

\section{ON WHALES, PAST AND PRESENT, AND THEIR PROBABLE ORIGIN}

\section{II.}

THOUGH the early stages by which whalebone has been modified from more simple palate structures are entirely lost to our sight, probably for ever, the conditions in which it now exists in different species of whales, show very marked varieties of progress, from a simple comparatively rudimental and imperfect condition, to what is perhaps the most wonderful example of mechanical adaptation to purpose known in any organic structure. These variations are worth dwelling upon for a few minutes, as they illustrate in an excellent manner the gradual modifications that may take place in an organ, evidently in adaptation to particular requirements, the causation of which can be perfectly explained upon Darwin's principle of natural selection.

In the Rorquals or fin-whales (genus Balcenoptera), found in almost all seas, and so well known off our own coasts, the largest blades in an animal of 7 ofeet in length do not exceed 2 feet in lengtb, including their hairy terminations; they are in most species of a pale horn colour, and their struc. ture is coarse and inelastic, separating into thick, stiff fibres, so that they are of no value for the ordinary purposes to which whalebone is applied in the arts. These animals feed on fish of considerable size, from herrings up to cod, and for foraging among shoals of these creatures the construction of their mouth and the structure of their baleen is evidently sufficient. This is the type of the earliest known extinct forms of whales, and it has continued to exist, with several slight modifications, to this day, because it has fulfilled one purpose in the economy of nature. Other purposes for which it was not ${ }^{x}$ Lecture delivered at the Royal Institution on the evening of Friday,
May 25, I883, by Prof. Flower, LL.D., F.R.S., P.Z.S., \&c. Concluded May 25, $188_{3}$, by Prof. Flower, LL.D., F.R.S., P.Z.S., \&c. Concluded
from p. 202 . 
sufficient have been supplied by gradual changes taking place, some of the stages of which are seen in the intermediate conditions still exhibited in the Megaptera, and the Atlantic and Southern Right Whales. Before describing the extreme modifications in the direction of complexity, I may mention, to show the range at present presented in the development of baleen, that there bas lately been discovered in the North Pacific a species called by the whalers the Californian Gray Whale (Rachianectes glaucus), which shows the opposite extreme of simplicity. The animal is from 30 to 40 feet in length; the baleen blades are only I 82 on each side (according to Scammon) and far apart, very short (the longest being from I4 to 16 inches in length), ligbt brown or nearly white in colour, and still more coarse in grain and inelastic than that of the Rorquals. The food of these whales is not yet known with certainty. They have been seen apparently seeking for it along soft bottoms of the sea, and fuci and mussels have been foun 1 in their stomachs.

In the Greenland Right Whale of the circumpolar seas, the Bow-head of the American whalers (Balana mysticetus), all the peculiarities which distinguish the head and mouth of the whales from other mammals have attained their greatest development. The head is of enormous size, exceeding one-third of the whole length of the creature. The cavity of the mouth is actually larger than that of the body, thorax and abtomen together. The upper jaw is very narrow, but greatly arched from before backwards, to increase the height of the cavity and allow for the great length of the baleen, the enormous rami of the mandibles are widely separated posteriorly, and have a still further outward sweep before they meet at the symphysis in front, giving the floor of the mouth the shape of an immense spoon. The baleen blades attain the number of 350 or more on each side, and those in the middle of the series have a length of ten or even twelve feet. They are blick in colour, fine and highly elastic in texture, and fray out at the inner edge and ends into long delicate, soft, älmost silky, but very tough hairs.

How these immensely long blades depending vertically from the palate were packed into a mouth the height of which was scarcely more than half their length, was a mystery not solved until a few years ago. Capt. David Gray of Peterhead, at my request, first gave us a clear idea of the arrangement of the baleen in the Greenland whale, and showed that the purpose of its wonderful elasticity was not primarily at least the benefit of the corset and umbrella makers, but that it was essential for the correct performance of its functions. It may here be mentioned that the modification of the mouth structure of the Right Whale is entirely in relation to its food. It is by this apparatus that it is enabled to avail itself of the minute but highly nutritious crustaceans and pteropods which swarm in immense shoals in the seas it frequents. The large mouth enables it to take in at one time a sufficient quantity of water filled with these small organisms, and the length and delicate structure of the baleen provides an efficient strainer or hair sieve by which the water can be drained off. If the baleen were, as in the Rorquals, short and rigid, and only of the length of the aperture between the upper and lower jaws when the mouth was shut, when the jaws were separated a space would be left beneath it through which the water and the minute particles of food would escape together. But instead of this, the long, slender, brush-like ends of the whalebone blades, when the mouth is closed, fold back, the front ones passing below the hinder ones in a channel lying between the tongue and the bone of the lower jaw. When the mouth is opened their elasticity causes them to straighten out like a bow that is unbent, so that at whatever distance the jaws are separated, the strainer remains in perfect action, filling the whole of the interval. The mechanical perfection of the arrangement is completed by the great development of the lower lip, which rises stiffly above the jaw-bone, and prevents the long, slender, flexible ends of the baleen being carried outwards by the rush of water from the mouth, when its cavity is being diminished by the closure of the jaws and raising of the tongue. The interest and admiration excited by the contemplation of such a beautifully adjusted piece of mechanism is certainly heightened by the knowledge that it has been brought about by the gradual adaptation and perfection of structures common to the whole class of animals to which the whale belongs.

Few points of the structure of whales offer so great a departure from the ordinary mammalian type as the limbs. The fore-limbs are reduced to the condition of simple paddles or oars, variously shaped, but always flattened and more or less oval in outline. They are freely movable at the shoulder-joint, where the humerus or upper-arm bone articulates with the shoulder-blade in the usual manner, but beyond this point, except a slight flexibility and elasticity, there is no motion between the different segments. The bones are all there, corresponding in number and general relations with those of the human or any other mammalian arm, but they are flattened out, and their contiguous ends, instead of presenting hinge-like joints, come in contact by flat surfaces, united together by strong ligamentous bands, and all wrapped up in an undivided covering of skin, which allows externally of no sign of the separate and many-jointed fingers seen in the skeleton.

Up to the year 1865 it was generally thought that there was nothing to be found between this bony framework and the covering skin, with its inner layer of blubber, except dense fibrous tissue, with bloot-vessels and nerves sufficient to maintain its vitality. Dissecting a large Rorqual, 67 feet in length, upon the beach of Pevensey Bay in that year, I was surprised to find lying upon the bones of the fore-arm well-developed muscles, the red fibres of which reached nearly to the lower end of these bones, ending in strong tendons, passing to, and radiating out on, the palmar surface of the hand. Circumstances then prevented me following out the details of their arrangement and distribution, but not long afterwards Prof. Struthers of Aberdeen had an opportunity of carefully dissecting the fore-limb of another whale of the same species, and he has recorded and figured his observations in the Journal of Anatomy for November, 1871. He found on the internal or palmar aspect of the limb three distinct muscles corresponding in attachments to the flexor carpi ulnaris, the flexor profundus digitorum, and the flexor longus pollicis of man, and on the opposite side but one, the extensor communis digitorum. ${ }^{1}$ Large as these muscles actually are, yet, compared with the size of the animal, they cannot but be regarded as rudimentary and being attached to bones without regular joints and firmly held together by unyielding tissues, theirfunctions must be reduced almost to nothing. But rudimentary as the muscles of the Fin-whales are, lower stages of degradation of the same structures are found in other members of the group. In some they are indeed present in form, but their muscular structure is gone and they are reduced in most of the toothed whales to mere fibrous bands, scarcely distinguishable from the surrounding tissue which connects the inner surface of the skin with the bone. It is impossible to contemplate these structures without having the conviction forced home that here are the remains of parts once of use to their possessor, now, owing to the complete change of purpose and mode of action of the limb, reduced to a condition of atrophy verging on complete disappearance.

The changes that have taken place in the hind-limbs are even more remarkable. In all known Cetacea (unless

I The muscles of the forearm of an allied species, Balanoptera rostrata, were described by Macalister in 1868 , and Perrin in 1870 . 
Platanista be really an exception) a pair of slender bones are found suspended a short distance below the vertebral column, but not attached to it, about the part where the body and the tail join. In museum skeletons these bones are often not seen, as, unless special care has been taken in the preparation, they are apt to get lost. They are, however, of much importance and interest, as their relations to surrounding parts show that they are the rudimentary representatives of the pelvic or hip bones, which in other mammals play such an important part in connecting the hind-limbs with the rest of the skeleton. The pelvic arch is thus almost universally present, but of the limb proper there is, as far as is yet known, not a vestige in any of the large group of toothed whales, not even in the great Cachalot or Sperm Whale, although it should be mentioned that it has never been looked for in that animal with any sort of care. With regard to the Whalebone Whales, at least to some of the species, the case is different. In these animals there are found, attached to the outer and lower side of the pelvic bone, other elements, bony or only cartilaginous as the case may be, clearly representing rudiments of the first and in some cases the second segment of the limb, the thigh or femur, and the leg or tibia. In the small Balanoptera rostrata a few thin fragments of cartilage, embedded in fibrous tissue attached to the side of the pelvic bone, constitute the most rudimentary possible condition of a hind-limb, and could not be recognised as such but for their analogy with other allied cases. In the large Rorqual, Balcenoptera musculus, 67 feet long, previously spoken of, I was fortunate enough in 1865 to find attached by fibrous tissue to the side of the pelvic bone (which was sixteen inches in length) a distinct femur, consisting of a nodule of cartilage of a slightly compressed, irregularly oval form, and not quite one inch and a half in length. Other specimens of the same animal dissected by Van Beneden and Prof. Struthers have shown the same; in one case, partial ossification had taken place. In the genus Megaptera a similar femur has been described by Eschricht; and the observations of Reinhardt have shown that the Greenland Right Whale (Balana mysticetus) has not only a representative of the femur developed far more completely than in the Rorqual, being from six to eight inches in length and completely ossified, but also a second smaller and more irregularly formed bone, representing the tibia. Our knowledge of these parts in this species has recently been greatly extended by the researches of Dr. Struthers of Aberdeen, who has published in the Journal of Anatomy for I88 I a most careful and detailed account of the dissection of several specimens, showing the amount of variation to which these bones (as with most rudimentary structures) are liable in different individuals, and describing for the first time their distinct articulation one with the other by synovial joints and capsular ligaments, and also the most remarkable and unlooked-for presence of muscles passing from one bone to the other, representing the adductors and flexors of mammals with completely developed limbs, but so situated that it is almost impossible to conceive that shey can be of any use ; the whole limb, such as it is, being buried deep below the surface, where any movement, except of the most limited kind, must be impossible. Indeed, that the movement is very limited and of no particular importance to the animal was shown by the fact that in two out of eleven whales dissected the hip-joint was firmly anchylosed (or fixed by bony union) though without any trace of disease. In the words of Dr. Struthers, "Nothing can be imagined more useless to the animal than rudiments of hind-legs entirely buried beneath the skin of a whale, so that one is inclined to suspect that these structures must admit of some other interpretation. Yet, approaching the inquiry with the most sceptical determination, one cannot help being convinced, as the dissection goes on, that these rudiments really are femur and tibia.
The functional point of view fails to account for their presence. Altogether they present for contemplation a most interesting instance of those significant parts, rudimentary structures."

We have here a case in which it is not difficult to answer the question before alluded to, often asked with regard to rudimentary parts, Are they disappearing or are they incipient organs? We can have no hesitation in saying that they are the former. All we know of the origin of limbs shows that they commence as outgrowths upon the surface of the body, and that the first-formed portions are the most distal segments. The limb, as proved by its permanent state in the lowest Vertebrates, and by its embryological condition in higher forms, is at first a mere projection or outward fold of the skin, which, in the course of development, as it becomes of use in moving or supporting the animal, acquires the internal framework which strengthens it and perfects its functions. It would be impossible, on any theory of causation yet known, to conceive of a limb gradually developed from within outwards. On the other hand, its disappearance would naturally take place in the opposite direction ; projecting parts which had become useless, being in the way, would, like all the other prominences on the surface of the whales, hair, ears, \&c., be removed, while the most internal, offering far less interference with successful carrying on the purposes of life, would be the last to disappear, lingering, as in the case of the Greenland Whale, long enough to reveal their wonderful history to the anatomist who has been fortunate enough to possess the skill and the insight to interpret it.

Time will not allow of more illustrations drawn from the structure of existing Cetacea; we turn next to what the researches of palæontology teach of the past history of the order. Unfortunately this does not at present amount to very much. As is the case with nearly all other orders of mammals, we know nothing of their condition, if they existed, in the mesozoic age. Even in the cretaceous seas, the deposits at the bottom of which are so well adapted to preserve the remains of the creatures which swam in them, not a fragment of any whale or whale-like animal has been found. The earliest Cetaceans of whose organisation we have any good evidence, are the Zeuglodons of the Eocene formations of North America. These were creatures whose structure, as far as we know it, was intermediate between that of the existing suborders of whales, having the elongated nasal bones and anterior position of the nostrils of the Mystacocetes, with the teeth of the Odontocetes, and with some characters more like those of the generalised mammalian type, than of any of the existing forms. In fact Zeuglodon is precisely what we might have expected a priori an ancestral form of whale to have been. The remarkable smallness of its cerebral cavity, compared with the jaws and the rest of the skull, so different front that of modern Cetaceans, is exactly paralleled in the primitive types of other groups of mammals. The teeth are markedly differentiated in different parts of the series. In the anterior part of both jaws they are simple, conical, or slightly compressed and sharp pointed. The first three of the upper jaw are distinctly implanted in the premaxillary bone, and so may be reckoned as incisors. The tooth which succeeds, or the canine, is also simple and conical, but it does not greatly exceed the others in size. This is followed by five teeth with two distinct roots and compressed pointed crowns, with denticulated cutting edges. It has been thought that there was evidence of a vertical succession of the molar teeth, as in diphyodont mammals, but the proof of this is not quite satisfactory. Unfortunately the structure of the limbs is most imperfectly known. A mutilated humerus has given rise to many conjectures; to some anatomists it appears to indicate freedom of motion at the elbow-joint, while to others its characters seem to be those of the ordinary Cetacea. 
Of the structure of the pelvis and hind limb we are at present in ignorance.

From the' middle Miocene period fossil Cetacea are abundant, and distinctly divided into the two groups now existing. The Mystacocetes, or Whalebone Whales, of the Miocene seas were, as far as we know now, only Balcenoptera, some of which (as the genus Cetotherium) were, in the elongated flattened form of the nasal bones, the greater distance between the occipital and frontal bone at the top of the head, and the greater length of the cervical vertebrre, more generalised than any now existing. In the shape of the mandible also, Van Beneden, to whose researches we are chiefly indebted for a knowledge of these forms, discerns some approximation to the Odontocetes. Right Whales (Balcena) have not been found earlier than the Pliocene period, and it is interesting to note that instead of the individuals diminishing in bulk as we approach the times we live in, as with many other groups of animals, the contrary has been the case, no known extinct species of whales equalling in size those that are now to be met with in the ocean. The size of whales, as of all other things whose most striking attribute is magnitude, has been greatly exaggerated; but when reduced to the limits of sober fact, the Greenland Right Whale of 50 feet long, the Sperm Whale of 60 , and the Great Northern Rorqual (Balanoptera Sibbaldii) of 80, exceed all other organic structures known, past or present. Instead of living in an age of degeneracy of physical growth, we are in an age of giants, but it may be at the end of that age. For countless ages impulses from within and the forces of circumstances from without have been gradually shaping the whales into their present wonderful form and gigantic size, but the very perfection of their structure and their magnitude combined, the rich supply of oil protecting their internal parts from cold, the beautiful apparatus of whalebone by which their nutrition is provided for, have been fatal gifts, which, under the sudden revolution produced on the surface of the globe by the development of the wants and arts of civilised man, cannot but lead in a few years to their extinction.

It does not need much foresight to divine the future history of whales, but let us return to the question with which we started, What was their probable origin?

In the first place, the evidence is absolutely conclusive that they were not originally aquatic in habit, but are derived from terrestrial mammals of fairly high organisation, belonging to the placental division of the class, animals in which a hairy covering was developed, and with sense organs, especially that of smell, adapted for living on land ; animals, moreover, with four completelydeveloped pairs of limbs on the type of the higher vertebrata, and not of that of fishes. Although their teeth are now of the simple homocont and diphyodont type, there is much evidence to show that this has taken place by the process of degradation from a more perfect type, even the tœtal teeth of Whalebone Whales showing signs of differentiation into molars and incisors, and many extinct forms, not only the Zeuglodons, but also true dolphins, as the Squalodons, having a distinct heterodont dentition, the loss of which, though technically called a "degradation," has been a change in conformity to the habits and needs of the individuals. So much may be considered very nearly if not quite within the range of demonstrated facts, but it is in determining the particular group of mammals from which the Cetacea arose that greater difficulties are met with.

One of the methods by which a land mammal may have been changed into an aquatic one is clearly shown in the stages which still survive among the Carnivora. The seals are obviously modifications of the land Carnivora, the Otaria, or Sea-Lions and Sea-Bears, being curiously intermediate. Many naturalists have been tempted to think that the whales represent a still further stage of the same kind of modification. So firmly has this idea taken root that in most popular works on zoology in which an attempt is made to trace the pedigree of existing mammals, the Cetacea are definitely placed as offshoots of the Pinnipedia, which in their turn are derived from the Carnivora. But there is to my mind a fatal objection to this view. The seal of course has much in common with the whale, inasmuch as it is a mammal adapted for an aquatic life, but it has been converted to its general fishlike form by the peculiar development of its hind.limbs into instruments of propulsion through the water; for though the thighs and legs are small, the feet are large and are the special organs of locomotion in the water, the tail being quite rudimentary. The two feet applied together form an organ very like the tail of a fish or whale, and functionlly representing it, but only functionally, for the time has I trust quite gone by when the Cetacea were defined as animals with the "hinder limbs united, forming a forked horizontal tail." In the whales, as we bave seen, the hind-limbs are aborted and the tail developed into a powerful swimming organ. Now it is very difficult to suppose that, when the hind-limbs had once become so well adapted to a function so essential to the welfare of the animil as that of swimming, they could ever have become reduced and their action transferred to the tail; - the animal must have been in a too helpless condition to maintain its existence during the transference, if it took place, as we must suppose, gradually. It is far more reasonable to suppose that whales were derived from animals with large tails, which were used in swimming, eventually with such effect that the hind-limbs became no longer necessary, and so gradually disappeared. The powerful tail, with lateral cutaneous flanges, of an American species of Otter (Pteronura sandbachii) or the still more familiar tail of the beaver, may give some idea of this member in the primitive Cetacea. I think that this consideration disposes of the principal argument that the whales are related to the seals, as most of the other resemblances, such as those in the characters of their teeth, are evidently analogous resemblances related to similarity of habit.

As pointed out long ago by Hunter, there are numerous points in the structure of the visceral organs of the Cetacea far more resembling those of the Ungulata than the Carnivora. These are the complex stomach, simple liver, respiratory organs, and especially the reproductive organs and structures relating to the development of the young. Even the skull of Zeuglodon, which has been cited as presenting a great resemblance to that of a seal, has quite as much likeness to one of the primitive piglike Ungulates, except in the purely-adaptive character of the form of the teeth.

Though there is, perhaps, generally more error than truth in popular ideas on natural history, I cannot help thinking that some insight has been shown in the common names attached to one of the most familiar of Cetaceans by those whose opportunities of knowing its nature have been greatest-_"Sea-Hog," "Sea-Pig," or "HerringHog" of our fishermen, Meerschwein of the Germans, corrupted into the French "Marsouin," and also "Porcpoisson," shortened into "Porpoise."

A difficulty that might be suggested in the derivation of the Cetacea from the Ungulata, arising from the latter being at the present day mainly vegetable feeders, is not great, as the primitive Ungulates were probably omnivorous, as their least modified descendants, the pigs, are still ; and the aquatic branch might easily have gradually become more and more piscivorous, as we know from the structure of their bones and teeth, the purely terrestrial members have become by degrees more exclusively graminivorous.

One other consideration may remove some of the difficulties that may arise in contemplating the transition of land mammals into whales. The Gangetic Dolphin (Platanista) and the somewhat related Inia of South 
America, which retain several rather generalised mammalian characters, and are related to some of the earliest known European Miocene forms, are both to the present day exclusively fluviatile, being found in the rivers they inhabit almost up to their very sources, more than a thousand miles from the sea. May this not point to the freshwater origin of the whole group, and thus account for their otherwise inexplicable absence from the Cretaceous seas?

We may conclude by picturing to ourselves some primitive generalised, marsh-haunting animals with scanty covering of hair like the modern hippopotamus, but with broad, swimming tails and short limbs, omnivorous in their mode of feeding, probably combining water plants with mussels, worms, and freshwater crustaceans, gradually becoming more and more adapted to fill the void place ready for them on the aquatic side of the borderland on which they dwelt, and so by degrees being modified into dolphin-like creatures inhabiting lakes and rivers, and ultimately finding their way into the ocean. Here the disappearance of the huge Enaliosaurians, the Ichthyosauri and Plesiosauri, which formerly played the part the Cetacea do now, had left them ample scope. Favoured by various conditions of temperature and climate, wealth of food supply, almost complete immunity from deadly enemies, andillimitable expanses in which to roam, they have undergone the various modifications to which the Cetacean type has now arrived, and gradually attained that colossal magnitude which we have seen was not always an attribute of the animals of this group.

Please to recollect, however, that this is a mere speculation, which may or may not be confirmed by subsequent palæontological discovery. Such speculations are, I trust, not without their use and interest, especially when it is distinctly understood that they are offered only as speculations and not as demonstrated facts.

\section{THE AMERICAN OBSERVATIONS OF THE ECLIPSE}

NEWS of the American observations of the last eclipse has now arrived, and although details are yet wanting, enough information has been sent to show us that, as was to be expected, the American observers have left their mark upon the work. The telegram given below has been forwarded to me by the editors of Science, and is one transmitted by Prof. Holden to Prof. Young on the arrival of the former at San Francisco :-

\section{"San Francisco, Cal., Fune II}

"American Eclipse Expedition arrived at St. Francisco June I I. Holden reports no Vulcan as bright as $5^{\frac{1}{2}}$ magnitude. Hasting's observations prove the corona to be largely a phenomenon of diffraction by the great change in lengh of 1474 line on east and west sides of sun. No black lines in corona spectrum but D. Full observations with grating spectroscopes, prismatic telescope, and integrating spectroscope, by Rockwell, Upton, and Brown. Contacts by Preston. English and French parties successful.

$$
\text { (Signed) }
$$

E. S. HOLDEN"

It will be seen from the above that the spectroscopic attack was a very strong one, and although the telegram gives only the results of the work of Prof. Hastings, these are of unusual interest. I propose, therefore, to devote attention to them in the present notice. It will, however, be well to anticipate my remarks by a prefatory notice of the eclipse work on which it throws light. For this purpose I can scarcely do better than give the following extract from an article which appeared in the Times on Monday last :-

"It was only really in the eclipse of I869 that we began to know anything about the corona, and it was only in the eclipse of 1870 that we began to appreciate what a very difficult problem was presented to us by that phenomenon. The then Astronomer-Royal and Prof. Maedler, to cite some among the eminent authorities writing after the eclipse of I860, had come to the conclusion that the corona was mainly a non solar phenomenon. That part of it, however, was undoubtedly solar was admitted by all, for the reason that it was seen before and after totality. In the eclipse of 1870 the idea that part of it was really non-solar was enormously strengthened by a comparison of observations maảe by different astronomers. Its shape seemed to change as the moon swept over it, and this obviously, if it were true, implied some action of the moon's edge and reflection by something between the observer and the moon. In 1871 , when the Government of India and the British Association took steps to have the corona photographed at the same time that it was carefully observed by the naked eye, the strange fact was first clearly indicated that the corona seen by the eye was a perfectly different thing to that recorded on the photographic plates. The explanation given at the time was that the coronal light was much more actinic than ordinary solar light of the same visible intensity, so that in the eye and on the photographic plate two different images were built up by different qualities of light proceeding from different sources. Hence the view was distinctly enunciated that the corona seen during eclipses was a dual phenomenon, partly solar, partly non-solar in its origin, the true solar corona being filamentous with variously-curved streamers, the visible corona being non-filamentous and consisting mainly of radial lines and rifts, extending to different distances from the edge of the moon "

This slight sketch may now be expanded by the following details. Thus, for instance, in March, I870, Prof. Young, discussing the then current views of the corona, wrote :- "It is not impossible that the so-called corona may be complex, some portion of its radiance may perhaps originate in our own atmosphere, though I do not yet find myself able to agree with the conclusion of Dr. Gould and Mr. Lockyer in this respect, and am strongly disposed to believe that the whole phenomenon is purely solar."

With reference to the eclipse of 1870 I wrote :--"At the commencement and end of totality, when the moon unequally covered the sun, the photographs have recorded an excess of light on the corona on the side where the limbs occur nearest in contact. I am told that this effect in one of Lord Lindsay's photographs is very striking; it is certainly so in one of Mr. Brothers'. In the drawings we have a slightly different effect. At the commencement
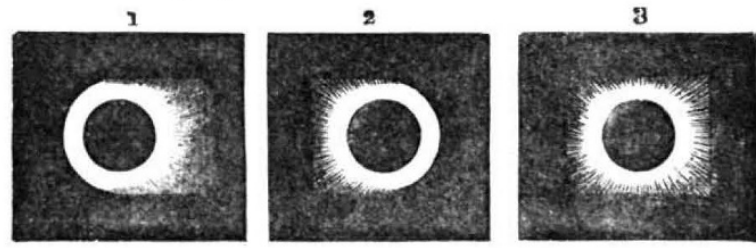

of totality, when the western or right-hand limbs were in contact, we get (see figure) I ; at the end of totality the appearance recorded was like 2 ; the picture at the middle of totality compounding both these appearances, and being roughly represented by 3 , in which the rectangular appearance comes out in its full strength."

Let us pass on to the eclipse of 187I. This was my description, written at the time, of what I saw :- "There, rigid in the heavens, was what struck everybody as a decoration, one that Emperors might fight for ; a thousand times more brilliant even than the star of India,- where we then were,- - a picture of surpassing loveliness, and giving one the idea of serenity among all the activity that was going on below, shining with a sheen as of silver essence, built up of rays almost symmetrically arranged round a bright ring above and below, with a marked absence of 